\title{
Problem solving applications in chemistry laboratory ${ }^{*}$
}

\author{
Senar TEMEL ${ }^{* *} \quad$ İnci MORGÍL ${ }^{* * *}$
}

\begin{abstract}
In this study, it was aimed to determine the performance of teacher candidates, who have participated in problem solving applications in chemistry laboratory, examine their performance in the final exams and to determine whether or not their performance is predicted by variables of perception on problem solving skill, scientific process skill and logical thinking skill or not. A semi-experimental design was used. 72 teacher candidates attended the study. Perception inventory of problem solving skill, tests of scientific process skill and logical thinking ability, evaluation form of problem solving skills, evaluation form of student reports and final exams were used as data collection tools. At the end of the study, the performance of each teacher candidate was determined. Through the statistical analysis, it was determined that $42 \%$ of the change in the performances of teacher candidates has been explained with variables of perception on problem solving skill, scientific process skill and logical thinking ability which are included in the model.
\end{abstract}

Keywords: Logical thinking ability, perception on problem solving skill, performance, problem solving, science process skill.

\footnotetext{
* This study was composed part of the PhD Thesis called "Problem Solving Applications in Chemistry Laboratory" and supported by The Scientific Technological Research Council of Turkey.

** Expert Dr., Hacettepe University, Faculty of Education, Ankara, Turkey. E-mail: senar@hacettepe.edu.tr

*** Prof. Dr., Hacettepe University, Faculty of Education, Ankara, Turkey. Retired Professor.
} 


\section{SUMMARY}

Purpose and Significance: In this study, it was aimed to i) determine the performance of teacher candidates, who participated in problem solving applications in chemistry laboratory, ii) examine their performance in the final exams and, iii) determine whether or not their performance is predicted by variables of perception of problem solving skill, scientific process skill and logical thinking ability.

Method: In this study one sample posttest model was used. Perception inventory of problem solving skill, tests of scientific process skill and logical thinking ability, evaluation form of problem solving skills, evaluation form of student reports and final exams were used as data collection tools. 72 teacher candidates participated in the study. Perception inventory of problem solving skills, tests of scientific process skill and logical thinking ability were implemented as pretest at the beginning of the study. On the completion of pretest implementation, problem solving applications in chemistry laboratory which are composed of 5 steps (YÖK, Dünya Bankas1, 1997) were carried out. Final exams were carried out subsequent to the applications. Perception inventory of problem solving skills, tests of scientific process skill and logical thinking ability were implemented as posttest at the last week of the term. Also, groups have submitted their reports, which included the applications they have done, at the same week.

Results: For this study, only posttest results were considered. Experiment reports prepared by groups were evaluated by researchers by means of evaluation form of student reports at the last week of applications. The all application steps that are carried out were observed by researchers and evaluation form of problem solving skills was filled in for each teacher candidate in the group. In the study, final exams that include questions necessitating higher and lower order thinking skills were put into practice on teacher candidates, and frequency and percentage distribution of the answers that teacher candidates were given were calculated. Multiple linear regression analysis was done to determine whether or not the performances of teacher candidates attending problem solving practices were predicted by variables of perceived problem solving skill, scientific process skill and logical thinking ability.

Discussion and Conclusions: When performance of teacher candidates was examined, it was determined that their performance generally are well. Also it was concluded that their performance on questions which 
necessitating lower order thinking skills are better than on questions necessitating higher order thinking skills. According to regression coefficient that is standardized, relative importance rank of predictive variables' effect on the performance of teacher candidates is: logical thinking ability, perceived problem solving skill and scientific process skill. When the result of t-test regarding the significance of regression coefficient was examined, it was found out that variables of perceived of problem solving skill and logical thinking ability has a meaningful prediction on the performances of teacher candidates, and scientific process skill does not have a meaningful effect. 


\title{
Kimya Laboratuvarında Problem Çözme Uygulamaları ${ }^{*}$
}

\author{
Senar TEMEL** \\ İnci MORGIL
}

\begin{abstract}
ÖZ. Çalı̧̧ada kimya laboratuvarında problem çözme uygulamalarına katılan öğretmen adaylarının; i) performanslarının belirlenmesi, ii) final sınavlarındaki performanslarının incelenmesi ve iii) performanslarının problem çözme becerisini algılama, bilimsel işlem becerisi ve mantıksal düşünme yeteneği değişkenleri tarafindan yordanıp yordanmadığının belirlenmesi amaçlanmıştır. Çalışmada tek grup son test model kullanılmıştır. Çalışmaya 72 öğretmen adayı katılmıştır. Veri toplama araçları olarak; problem çözme becerisini algılama envanteri, bilimsel işlem becerisi ve mantıksal düşünme yeteneği testleri, problem çözme becerilerini değerlendirme formu, öğrenci raporlarını değerlendirme formu ve final sınavları kullanılmışıır. Çalışmanın sonucunda öğretmen adaylarının performansları belirlenmiştir. Yapılan istatistiksel analizler sonucunda, öğretmen adaylarının performanslarındaki değişimin \%42'sinin modele dahil edilen problem çözme becerisini algılama, bilimsel işlem becerisi ve mantıksal düşünme yeteneği değişkenleri tarafindan birlikte yordandığı belirlenmiştir.
\end{abstract}

Anahtar Sözcükler: Mantıksal düşünme yeteneği, problem çözme becerisini algılama, performans, problem çözme, bilimsel işlem becerisi.

\footnotetext{
* Bu çalışma "Kimya Laboratuvarında Problem Çözme Uygulamaları" adlı Doktora tez çalıșmasııın bir bölümünden özetlenerek hazırlanmış ve Türkiye Bilimsel ve Teknolojik Araştırma Kurumu tarafından desteklenmiştir.

** Uzm. Dr., Hacettepe Üniversitesi Eğitim Fakültesi Ankara, Türkiye. E-mail: senar@hacettepe.edu.tr

*** Prof. Dr. Hacettepe Üniversitesi Eğitim Fakültesi Ankara, Türkiye, Emekli Öğretim Üyesi
} 


\section{GíRiș}

Fen bilimi eğitimi ve amaçları: Fen bilimi eğitiminin temel amaçlarından birincisi, özel bir alanda organize olmuş bilginin elde edilmesi ikincisi ise bu alanla ilgili problemleri çözme becerisidir (Gabel ve Bunce, 1994; Heyworth, 1999; Stamovlasis ve Tsaparlis, 2000; Tsaparlis, Kousathana ve Niaz, 1998; Akt. Lee, Tang, Goh ve Chia, 2001).

Problem çözme, kişinin hedefine ulaşmasında karşılaştığı engellere meydan okuma sürecidir. Literatürde farklı problem çözme tanımları yapılmıştır. Wheatley (1984)'e göre problem çözme, ne yapacağını bilmediğin zaman ne yaptığındır. Cardellini (2006)'ye göre ise, iyi bilinen formüllere sayıların yerleştirilmesinden daha fazlasıdır. Altun ve Arslan (2006)'a göre problem çözme, araştırmacıların iki temel nedenle yoğun ilgi gösterdiği bir konudur. Birincisi, her tür güçlüğü ortadan kaldırmada işe yarayacak bir düşünme şeklidir, ikincisi, öğretimde kaliteyi artıracak bir öğrenme yaklaşımıdır. Saygılı (2000)'ya göre hızla değişen ve gelişen günümüz toplumunda insanlar, değişime ve gelişime ayak uydurabilmek için, karşılaştı̆̆ problemlerin üstesinden gelmek zorundadır. Aynı şekilde, bilim adamları da, bilinen gerçeklerden bilinmeyen gerçeklere doğru olan çalışma süreçlerinde birçok problemle karşılaşmaktır. Amaçlarına ulaşmak için, bu süreçlerde ortaya çıan problemlerin ve engellerin üstesinden gelme yeteneğine sahip olmak zorundadır (Lee ve diğ., 2001). Bunun oluşmasında kişinin problemleriyle baş etme konusunda kendini değerlendirmesi son derece önemlidir. Problem çözmede olumlu benlik algısına sahip kişiler, gerçek problem çözmede daha başarılı olabilmektedir (Güçlü, 2003). Bu nedenle, öğrencilerin fen bilimi eğitimi boyunca problem çözme becerilerini geliştirmek önemlidir.

Fen bilimi eğitiminde problem çözme becerilerinin kazandırılmasında problem çözme öğretiminin öneminin anlaşılması ve öğrencilerin karşılaştıkları problemlerin üstesinden gelmelerine yardım etmenin yollarını bulmak gerekmektedir (Lee ve dĭ̆., 2001). Reif, Larkin ve Brackett, (1976) problem çözmenin kolayca öğretilemeyeceğini ileri sürmüşlerdir. Fakat problem çözmenin bir parçası olarak kullanılabilen spesifik becerileri ve usulleri öğretmek olasıdır. Bunun için en iyi yol, öğrencilerin kimyada açık uçlu problemlerle karşılaşma olanaklarını artırmak ve onlara gerekli desteği sağlamaktır. Öğrenciler çözümü için herhangi bir sürecin öğretilmediği yeni problemlerle karşı karşıya bırakılmalıdır (Herron ve Greenbowe, 1986). Asieba (1993); Collins, Brown ve Newman (1989); Keith, (1993); Taconis (2001)'e göre problem çözme becerisinin gelişiminde öğrencilere rehberlik ve dönüt sağlama, stratejik metotları tanıtma ve bu metotları kullanmaları için model olma önemlidir (Akt. Jeon, Huffman ve Noh, 2005). 
Fen bilimi eğitiminin temel amaçlarından biri de, öğrencilere bilimsel işlem becerilerini kazandırmak olarak belirlenmiştir (Karahan, 2006). Germann (1994)'a göre bilimsel işlem becerileri, bilim adamlarının çalışmaları sırasında kullandıkları becerilerdir. Öğrencilerin araştırma, sorgulama, eleştirel düşünme, problem çözme becerileri geliştirmelerini, yaşam boyu öğrenen bireyler olmalarını ve yaşadıkları çevre hakkında merak duygusunu sürdürmelerini sağlamayı hedefleyen fen bilimi eğitiminde ögrencilerin bilimsel bilgi üretmelerini ve bilimin doğasını yaşayarak öğrenmelerini sağlayan bilimsel işlem becerilerini kazanmaları son derece önemlidir (Aydoğdu, 2006).

Fen bilimi eğitiminin bir diğer amacı da, mantıksal düşünme diğer bir deyişle problem çözme becerisidir (Sonmaz, 2002). Korkmaz (2002)'a göre mantıksal düşünme yeteneği, bireyin çeşitli zihinsel işlemler yaparak bir sorunu çözmesi veya bir takım soyutlama ve genellemeler yaparak ilke ve yasalara ulaşmasıdır (Akt.Yaman, 2005). Mantıksal düşünme bir süreçtir ve bu yeteneğin kazandırılması sürecin amaçlarındandır (Düşünme, 2006; Akt. Bozdoğan, 2007). Aşkar (1989)'a göre mantıksal düşünme problem çözmenin alt aşamalarındandır. Bu nedenle karmaşı problemleri çözebilen insanların mantıksal düşünme ve muhakeme yapma güçlerinin yeterli olduğu düşünülebilmektedir. Mantıksal düşünme yeteneğinin geliştirilmesi için de problem çözme öğretimi dikkate alınmalıdır. (Akt. Bozdoğan, 2007).

Laboratuvarda problem çözme yaklaşımı: Chiappetta ve Koballa (2002)'ya göre, laboratuvarların verimliliğinin artırılması ve anlamlı öğrenmenin gerçekleştirildiği ortamlara dönüştürülmesi için son yıllarda çeşitli yaklaşımlar geliştirilmiştir. Bu yaklaşımlardan biri laboratuvarda problem çözme yaklaşımıdır. $\mathrm{Bu}$ yaklaşımın kullanımı ile laboratuvar çalışmaları, kimya müfredatında daha doğru kullanım amacına yönelik olarak yeniden düzenlenmiştir (Wilson, 1987). Laboratuvarlar, teknik kavramların gerçek dünya içeriğinde uygulanması ve birleştirilmesi için ideal ve elverişli ortamlardır (Gallet, 1998). Fakat geleneksel kimya laboratuvar deneyleri, çok fazla düşünmenin ya da hazırlı̆̆ın gerekli olmadığı bir tarzda yapılmaktadır. Öğrenciler, yemek kitabındaki tariflere benzer şekilde laboratuvar süreçlerini takip etmektedir (Neeland, 1999). Bu durumu düzeltme çabasıyla bazı kimya eğitimcileri, laboratuvarda problem çözme yaklaşımını kullanarak daha iyi sonuçlar elde etmiştir (Wilson, 1987). Wilson (1987), çalışmasında laboratuvarda problem çözme yaklaşımının kullanımıyla öğrencilerin deneysel tasarım pratiği edinmesine olanak sağlamıştır. Çalışmanın sonucunda, laboratuvarda problem çözme yaklaşımındaki başarı, laboratuvar çalışmaları için önemli bir güdü olarak bulunmuştur. Neeland (1999)'ın, organik kimya laboratuvarında kullanılan problem çözme yaklaşımının başarısını rapor etmek ve bazı öğrencilerin bu 
yaklaşıma karşı olan beklenen çekingenliğinin üstesinden gelmek için yaptığı çalışması sonucunda, öğrenciler deneylerini kontrol etmede heyecan duymuşlar ve laboratuvarda daha güvenli olan, daha iyi düşünen bireyler haline gelmiştir. Gallet (1998)'in laboratuvarda problem çözme yaklaşımına yer verdiği çalışması sonucunda ise, öğrenciler bu problem çözme uygulamasının onların kimyasal prensipleri anlamalarına ve uygulamalarına yardım eden en uygun yöntemlerden biri olduğunu belirtmişlerdir.

\section{Çalışmanın Önemi}

Bilgi ve teknoloji çağını anlamak ve ona ayak uydurabilmek için, araştırma, sorgulama ve karşılaşılan problemleri bilimsel yöntemlerle çözebilme becerisine sahip olmak önemlidir. Bilgiyi gözlemler yaparak, anlamlı sorular sorarak, bunlara yanıtlar arayarak edinen kişiler yetiştirmek için yaparak yaşayarak öğrenme gibi kalıcı öğrenme sağlayan öğrenme ortamları hazırlamak gerekmektedir. Laboratuvar çalışmaları da, bu sürece en fazla katkı sağlayan unsurlardan biridir (Erbaş, Şimşek ve Çınar, 2005). Fakat çeşitli çalışmalar incelendiğinde geleneksel tarzda yürütülen laboratuar uygulamalarının eksik yönlerinin olduğu görülmektedir. Renner (1986), çalışmasında laboratuvar uygulamalarının önemine değişmiş fakat laboratuvarların gerçek rolünün yanlış anlaşıldığını vurgulamıştır. Germann, Hoskins ve Auls (1996) çalışmalarında, öğrencilerin sorular sordukları, hipotezler oluşturdukları, gözlemler yaptıkları, deneyler tasarladıkları ve sonuçlarını tahmin ettikleri etkinliklere yönlendirilmediklerini ortaya koymuşlardır. Finster (1991) çalışmasında çoğu üniversite laboratuvarlarının eğitimci tarafından açıklanmış ve tartışılmış olan gerçeği kanıtlamak için öğrencilerin veri toplamak zorunda oldukları fikrini güçlendirme eğiliminde olduğunu ileri sürmüştür. Bu eksikliklerden hareketle çalışmada geleneksel laboratuvar uygulamalarından farklı olan laboratuvarda problem çözme uygulamalarına yer verme ve bu uygulamalar sonucunda öğretmen adaylarının performanslarını inceleme amaçlanmıştır. Ayrıca bilimsel işlem becerilerinin ve mantıksal düşünme yeteneklerinin kullanımının özellikle üniversite seviyesindeki öğrencilerin problem çözme performanslarına etkisinin olup olmadığını belirleme amaçlanmıştır. Literatür incelendiğinde problem çözme odaklı laboratuvar uygulamaları sonucunda elde edilen problem çözme performansı ile bu beceriler arasındaki ilişkileri inceleyen çalışmaların olmadığı görülmüştür.

\section{Çalışmanın Amacı}

Çalışmada kimya laboratuvarında problem çözme uygulamalarına katılan öğretmen adaylarının; i) performanslarının belirlenmesi, ii) final sınavlarındaki performanslarının incelenmesi ve iii) performanslarının 
problem çözme becerisini algılama (PÇBA), bilimsel işlem becerisi (BİB) ve mantıksal düşünme yeteneği (MDY) değişkenleri tarafından yordanıp yordanmadığının belirlenmesi amaçlanmıştır. Bu amaçla aşağıdaki alt problemlere yanıtlar aranmıştır:

- Öğretmen adaylarının kimya laboratuvarında problem çözme uygulamalarından sonra performansları nasıldır?

- Öğretmen adaylarının kimya laboratuvarında problem çözme uygulamalarından sonra final sinavlarındaki performansları nasıldır?

- PÇBA, BİB ve MDY değişkenleri kimya laboratuvarında problem çözme uygulamalarına katılan öğretmen adaylarının performanslarının anlamlı bir yordayıcısı mıdır?

\section{YÖNTEM}

\section{Çalışmanın Modeli}

Çalışmada tek grup son test model kullanılmıştır. Çalışma her iki öğretim yılında uygulamaların yürütüldüğü derslere kayıtlı öğretmen adayı sayısının sınırlılığından dolayı tek grup ile yürütülmüş ve bu model tercih edilmiştir.

\section{Çalışma Grubu}

Çalışmaya 2006-2007 Öğretim Y1lı Güz Döneminde, Hacettepe Üniversitesi, Eğitim Fakültesi, Kimya Eğitimi Anabilim Dalı 4.sınıfta öğrenim gören 42 ve 2007-2008 Öğretim Y1lı Güz Döneminde, Hacettepe Üniversitesi, Eğitim Fakültesi, Kimya Eğitimi Anabilim Dalı 4.sınıfta öğrenim gören 30 olmak üzere toplam 72 öğretmen adayı katılmıştır.

\section{Veri Toplama Araçları}

Problem çözme becerisini algllama envanteri (PÇBAE). PÇBAE, kişinin problem çözme becerileri konusunda kendini algılayışını ölçmek amaciyla kullanılmaktadır. Heppner ve Petersen (1982) tarafindan geliştirilen envanterin Türkçe'ye çevirisi ilk olarak Akkoyun ve Öztan, 1988; Akt. Taylan, 1990) daha sonra Taylan (1990) ve Savaşır ve Şahin (1997) tarafından yapılmıştır. PÇBE, 35 maddeden oluşan 6'lı Likert tipi bir ölçektir. Savaşır ve Şahin (1997) yaptıkları çalışma sonucunda, PÇBAE'nin "Problem çözme yeteneğine güven" (Alpha katsayısı = .85), "Yaklaşmakaçınma" (Alpha katsayısı $=.84)$ ve "Kişisel kontrol" (Alpha katsayısı = .72) olmak üzere üç faktörden (alt ölçekten) oluştuğunu belirlemiştir. Envanterin güvenirlik çalışmasında envanterin tümü için Cronbach Alpha iç 
tutarlılık katsayısı .90 , alt ölçekler için elde edilen katsayılar ise .70 ile .85 arasında bulunmuştur.

Bilimsel işlem beceri testi (BIBBT). Testin orijinali, Okey, Wise ve Burns (1982) tarafından geliştirilmiş, Türkçe'ye çevirisi ve uyarlaması Geban, Aşkar ve Özkan (1992) tarafından yapılmıştır. Test, 4 seçenekli çoktan seçmeli 36 sorudan oluşmaktadır. Testte, problemdeki değişkenleri tanımlayabilme (12), hipotez kurma, tanımlama (8), işlemsel açıklamalar getirebilme (6), problem çözümü için gerekli incelemeler tasarlama (3), grafik çizme ve yorumlama (7) yeteneklerini ölçen sorular bulunmaktadır. Testin güvenirlik katsayıs1 .82 olarak bulunmuştur.

Mantıksal düşünme yeteneği testi (MDYT). Testin orjinali Tobin ve Copie (1981) tarafından geliştirilmiştir. MDYT, değişkenleri anlayabilme ve hakim olabilme, orant1 kurarak korelasyon sağlayabilme, ihtimalleri değerlendirerek mantık yürütmeye dayalı 10 soru içermektedir. Testin Türkçe'ye çevirisi ve uyarlaması Geban, Aşkar ve Özkan (1992) tarafından yapılmış ve güvenirlik katsayısı .77 olarak bulunmuştur.

Problem çözme becerilerini değerlendirme formu (PÇBDF). PÇBDF, araştırmacıların öğretmen adaylarını bireysel olarak değerlendirdiği bir formdur (Lynch, Wolcott ve Huber, 2000). Öğretmen adaylarının problem çözme becerileri, formda yer alan ölçütlere (Problemin doğasını ve ilgili bilgiyi ayırt etme, açık uçlu bir problem düzenleme, açık uçlu bir problemi çözme, açık uçlu bir problemi yeniden düzenleme) göre değerlendirilmektedir. Formda yer alan her beceriye, gösterilen becerinin niteliğine göre 0 ile 4 arasında puanlar verilmektedir. Uzman görüşü alınarak formun görünüş ve kapsam geçerliği sağlanmaya çalışmıştır. Formun güvenirliğinin sağlanması amacıyla her iki araştırmacı her öğretmen adayı için ayrı olarak bu formu doldurmuş ve araştırmacıların verdikleri puanlar arasındaki tutarlılığa bakılmıştır. Yapılan Pearson korelasyon analizi sonucunda iki araştırmacı arasındaki uyum .89 olarak bulunmuştur.

Ö̆rrenci raporlarını değerlendirme formu (ÖRDF). ÖRDF (chem.ntci.on.ca/sch4u/InquiryRubric.pdf), her bir grubun ürünü olan ve laboratuvar uygulamalarının ardından gruplar tarafindan hazırlanan raporları değerlendirmek için araştırmacılar tarafından uyarlanmış bir formdur. Söz konusu formda yer alan değerlendirme ölçütlerine (amaç, materyaller ve prosedür, hipotez, sonuçlar, tartışma) 1 ile 4 arasında puanlar verilmektedir. Formun güvenirliğinin sağlanması amacıyla her iki araştırmacı her grubun deney raporu için ayrı olarak bu formu doldurmuş ve araştırmacıların verdikleri puanlar arasındaki tutarlılığa bakılmıştır. Yapılan Pearson korelasyon analizi sonucunda iki araştırmacı arasındaki uyum .87 olarak bulunmuştur. 
Final sınavları. Problem çözme yaklaşımı, bilişsel alanda öğrenmeyi kapsadığı ve zihnin analiz etme, genelleme ve sentez yapma gibi yüksek bilişsel fonksiyonları kullanmasını gerektirdiği için çalışmada Bloom (1965) tarafindan yapılan taksonomiye göre oluşturulmuş alt ve üst düzey düşünme becerileri gerektiren soruların yer aldığı final sınavları uygulanmıştır. Çalışmanın yürütüldüğü birinci öğretim yılında, 8 açık uçlu sorudan oluşan, ikinci öğretim yılında 6 açık uçlu sorudan oluşan final sınavları araştırmalar tarafindan geliştirilmiş̧ ve alan uzmanlarına incelettirilerek geçerliği sağlanmaya çalışılmıştır. Final sınavları her iki araştırmacı tarafından ayrı ayrı değerlendirilmiş ve bulgular nicel olarak sunulmuştur.

\section{Öğretim Süreci}

Çalışma, uygulamalarının niteliğine uygun olarak, birinci öğretim yılında bilgisayar destekli kimya öğretimi uygulamaları, öğretim modelleri ve materyal geliştirmeye yönelik etkinliklerin gerçekleştirildiği "Kimya Eğitimi II" ve ikinci öğretim yılında ortaöğretim kimya öğretimine yönelik deney uygulamalarının gerçekleştirildiği "Ortaöğretimde Kimya Deneyleri”" dersleri kapsamında yürütülmüştür. Her iki dönemde 5 adımdan oluşan kimya laboratuvarında problem çözme uygulamaları (YÖK Dünya Bankası, 1997) gerçekleştirilmiştir. Çalışmanın başlangıcında PÇBAE, BİBT ve MDYT öntest olarak uygulanmıştır. Öntest uygulamasından sonra, öğretmen adaylarının problem çözmenin ne anlama geldiği, problem çözme sürecinin önemi ve nasıl gerçekleştirildiği hakkındaki fikirleri alınmış ve bu konularda onlarla küçük bir tartışma yapılmıştır. Daha sonra kimya laboratuvarında problem çözme uygulamalarının ne olduğu, uygulamaların hangi adımlardan oluştuğu ve bu adımlarda neler yapılması gerektiği hakkında bilgi verilmiş ve böylece uygulama öğretmen adaylarına tanıtılmıştır. Bu süreç dönemin ilk haftasında gerçekleştirilmiştir. İkinci hafta öğretmen adaylarından gruplar oluşturmaları istenmiştir. Birinci öğretim yılında öğretmen adayları rasgele 5-6 kişiden oluşan 8 grup oluştururken, ikinci öğretim yılında rasgele 6 kişiden oluşan 5 grup oluşturmuştur. Yine aynı hafta uygulamanın ilk adımı (Problem durumu) gerçekleştirilmiştir. Her gruba bir problem durumu sunulmuş ve öğretmen adaylarına bir sonraki hafta problemlerini kesin bir dille belirlemelerinin isteneceği belirtilmiştir. Birinci öğretim yılında 8 , ikinci öğretim yılında 5 olmak üzere toplam 13 problem durumu sunulmuştur. Üçüncü hafta yani uygulamanın ikinci adımının (Problemi belirleme) gerçekleştirildiği hafta, gruplar problem durumlarını basitleştirmeye, incelenecek olayları incelenmeyecek olaylardan ayırt etmeye çalışmıştır. Daha sonra kendilerine verilen problem durumlarını basamaklara veya alt problemlere bölmüş ve problemlerini açık bir dille ifade etmiştir. Grupların belirledikleri problemler araştırmacılar tarafından 
kontrol edilmiştir. Dördüncü hafta yani uygulamanın üçüncü adımının (Hipotez Kurma) gerçekleştirildiği hafta, gruplar problemlerini çözmek için gerekli olan tüm teknik ve teorik soruları belirlemiştir. Daha sonra her grup, kendi arasında görev paylaşımı yapmış ve problemlerine olası çözüm yolları aramaya başlamıştır. Bu amaçla gruplar 3 hafta boyunca problemleri hakkında bilgi toplamak için kütüphaneden ve çeşitli kaynaklardan yararlanmıştır. Bilgi toplama adımından sonraki hafta ise, her grubun önerdiği çözüm yolları toplanmış ve olası çözüm yollarından biri denenmek üzere seçilmiştir. Bu çözüm yolları uygulamayı yürüten araştırmacılar tarafından kontrol edilmiştir. Yine bu adımda gruplar, problemlerini çözmek için hipotezlerini oluşturmuş ve seçtikleri en olası çözüm yolunu bir deney önerisi haline getirmiştir. Dördüncü adımda (Çözüm yolunu deneme) uygulamayı yürüten araştırmacılar rehberliğinde önerdikleri deneyleri kimya laboratuvarında yapmıştır. Deney aşaması gerçekleştirilirken, deneylerini yapan gruplar, yaptıkları deneyler sonucunda elde ettikleri sonuçları genelleyerek kendi ifadeleriyle yazmıştır. Uygulamanın beşinci ve son adımında (Geriye dönme) yapılan deneyler sonucunda hipoteze uygun sonuçlar alamayan gruplar geri dönerek çözüm adımlarını gözden geçirmiş, hatalı yapıldığından şüphelenilen basamaktan başlayarak işlemleri tekrar etmiştir. Yeniden deney yapmaya ihtiyaç duyan gruplar laboratuvarda tekrar deney yapmıştır. Daha sonra her grup kendi uygulama adımlarını birbirlerine vermiştir. Bir sonraki hafta öğretmen adaylarına final sınavları uygulanmıştır. Dönemin son haftasında ise, PÇBAE, BİBT ve MDYT sontest olarak uygulanmıştır. Ayrıca bu hafta gruplar amaçlarını, gözlemlerini, veri analizlerini, hipotezlerini, çalışma planlarını, ulaştıkları sonuçları kapsayan raporlarını araştırmacılara teslim etmiştir.

\section{BULGULAR}

Çalışma doktora tez çalışmasının bir bölümünden özetlenerek hazırlandığı için bulgular kısmında sadece son test sonuçları dikkate alınmıştır.

\section{Birinci Alt Probleme İlişkin Bulgular}

Çalışmanın birinci alt problemi ile ilişkili olarak; öğretmen adaylarının performansları belirlenmiştir. Bunun için gruplar tarafından hazırlanan deney raporları araştırmacılar tarafından ÖRDF ile değerlendirilmiştir. Uygulama adımlarının tümü araştırmacılar tarafından gözlenmiş ve gruplardaki her bir öğretmen adayı için PÇBDF doldurulmuştur (Performans değerlendirmelerinde elde edilen puanlar 100'lük puanlamaya çevrilmiştir). PÇBDF ve ÖRDF'dan elde edilen puanların \% 30'u, final sınavlarından elde 
edilen puanın \% 40'1 alınarak her bir öğretmen adayının performansı belirlenmiştir. Öğretmen adaylarının performanslarının en düşük 58, en yüksek 94 olduğu belirlenmiştir. Öğretmen adaylarının performans ortalamaları ise $\bar{X}=76.64$ olarak bulunmuştur.

\section{İkinci Alt Probleme İlişkin Bulgular}

Çalışmanın ikinci alt problemi ile ilişkili olarak; öğretmen adaylarının final sınavlarındaki performansları belirlenmiştir. Alt ve üst düzey düşünme becerileri gerektiren sorulara verdikleri cevapların frekans ve yüzde dağılımları hesaplanmıştır. Bu frekans ve yüzdeler, Tablo 1 ve Tablo 2'de verilmektedir.

Tablo1. Birinci ögretim yılında uygulanan final sınavı sorularına öğretmen adaylarının verdikleri cevapların frekans ve yüzde dă̆llımları

\begin{tabular}{|c|c|c|c|c|c|c|c|c|c|c|}
\hline & \multicolumn{2}{|l|}{ Sorular } & \multicolumn{2}{|c|}{$\begin{array}{l}\text { Doğru } \\
\text { cevap }\end{array}$} & \multicolumn{2}{|c|}{$\begin{array}{c}\text { Kismen } \\
\text { doğru } \\
\text { cevap }\end{array}$} & \multicolumn{2}{|c|}{$\begin{array}{l}\text { Yanlış } \\
\text { cevap }\end{array}$} & \multicolumn{2}{|c|}{ Cevapsız } \\
\hline & & & $f$ & $\%$ & $f$ & $\%$ & $f$ & $\%$ & $\mathrm{f}$ & $\%$ \\
\hline \multirow{4}{*}{ 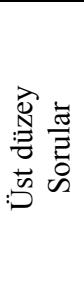 } & $\begin{array}{l}\text { Analiz } \\
\text { Seviyesi }\end{array}$ & 2.soru & 20 & 47.6 & 20 & 47.6 & 2 & 4.8 & 0 & 0 \\
\hline & $\begin{array}{l}\text { Analiz } \\
\text { Seviyesi }\end{array}$ & 4.soru & 0 & 0 & 28 & 66.7 & 14 & 33.3 & 0 & 0 \\
\hline & $\begin{array}{l}\text { Değerlendirme } \\
\text { seviyesi }\end{array}$ & 6. soru & 0 & 0 & 2 & 4.8 & 40 & 95.2 & 0 & 0 \\
\hline & $\begin{array}{l}\text { Değerlendirme } \\
\text { seviyesi }\end{array}$ & 8.soru & 0 & 0 & 30 & 71.4 & 12 & 28.6 & 0 & 0 \\
\hline \multirow{4}{*}{ 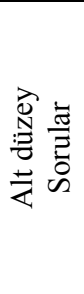 } & $\begin{array}{l}\text { Bilgi } \\
\text { Seviyesi }\end{array}$ & 1.soru & 22 & 52.4 & 0 & 0 & 18 & 42.8 & 2 & 4.8 \\
\hline & $\begin{array}{l}\text { Uygulama } \\
\text { Seviyesi }\end{array}$ & 3.soru & 17 & 40.5 & 0 & 0 & 25 & 59.5 & 0 & 0 \\
\hline & $\begin{array}{l}\text { Bilgi } \\
\text { Seviyesi }\end{array}$ & 5.soru & 30 & 71.4 & 6 & 14.3 & 6 & 14.3 & 0 & 0 \\
\hline & $\begin{array}{l}\text { Kavrama } \\
\text { Seviyesi }\end{array}$ & 7.soru & 11 & 26.2 & 31 & 73.8 & 0 & 0 & 0 & 0 \\
\hline
\end{tabular}

Tablo1 incelendiğinde, öğretmen adaylarının alt düzey düşünme gerektiren "Bilgi" seviyesinde yer alan 1. soruya "Avagadro yasasinı tanımlayınız" \%52.4 oranında, 5. soruya "Demir korozyonunun (paslanma) gerçekleşmesi için gerekli şartlar nelerdir?" ise \%71,4 oranında doğru cevap verdiği görülmüştür. Öğretmen adayları "Kavrama seviyesinde yer alan 7. Soruya "Sert suların neden olduğu problemleri sıralayınız" $\% 73.8$ oranında kısmen doğru cevap verirken, "Uygulama" seviyesinde yer alan 3. soruya "Kimyasal dengeyi sıcaklık değişiminin nasıl etkilediğini bir tepkime üzerinde gösteriniz" \%59.5 oranında yanlış cevap vermiştir. 
Öğretmen adaylarının üst düzey düşünme gerektiren sorulardaki performansları incelendiğinde, "Analiz" seviyesinde yer alan sorulardan biri olan 2. soruya "Tepkime 1sis1 ile tepkimelerin ekzotermik ya da endotermik olarak gerçekleşmesi arasındaki ilişkiyi açıklayınız" \%47.6 oranında doğru cevap verdiği, 4. soruya "Toprağın tamponlanma özelliğinin olmamasının bitkiler açısından olumsuz etkileri nelerdir?" \%66.7 oranında kısmen doğru cevap verdiği görülmüş̧ür. Öğretmen adayları "Değerlendirme" seviyesinde yer alan sorulardan biri olan 6. soruya "Aktif olmayan metal kullanımı her türlü korozyon olayını çözmek için kullanılabilir mi?” \% 95.2 oranında yanlış cevap verirken, 8. soruya "Aktif kömür filtreleri saf içme suyu sağlamak için kullanılabilir mi?" \%71.4 oranında kısmen doğru cevap vermiştir. Ayrıca öğretmen adaylarının bu sorulara verdikleri cevaplar soru bazında incelenmiştir.

Öğretmen adaylarını \%52,4'ü "Bilgi" seviyesinde yer alan 1. soruya doğru cevap vermiştir. Öğretmen adaylarının verdikleri cevaplar incelendiğinde, avagadro yasası yerine avagadro sayısını tanımladıkları görülmüştür. Bazı öğretmen adayları ise, bir gazın mol sayısı ile kapladığı hacmin doğru orantılı olduğunu ifade etmiş fakat bu ifadenin hangi şartlar altında geçerli olduğunu belirtmemiştir.

Ögretmen adaylarının \% 47,6's1 "Analiz" seviyesinde yer alan 2. soruya doğru cevap, \%47,6's1 kısmen doğru cevap vermiştir. Cevaplar incelendiğinde, bazı adayların ekzotermik ve endotermik tepkimeler gerçekleşirken 1sı alındığını ya da verildiğini belirtmelerine rağmen, bu durumlarda tepkime 1sısının neyi ifade ettiğini belirtmedikleri görülmüştür. Öğretmen adaylarının bir kısmının tepkime ısısının ne olduğunu bilmedikleri ve tepkime 1sıs ile tepkimelerin endotermik ya da ekzotermik gerçekleşmesi arasındaki ilişkiyi tam olarak kuramadıkları görülmüştür.

Öğretmen adaylarının \%59,5'i "Uygulama" seviyesinde yer alan 3. soruya yanlış cevap, \%40,5'i doğru cevap vermiştir. Doğru cevap veren öğretmen adaylarının dengedeki sistemin sıcaklığının değişmesi ile dengenin nasıl değişeceğini, tepkimenin ekzotermik yada endotermik oluşunun belirlediğini ifade ettikleri görülmüştür. Bazı öğretmen adaylarının kimyasal denge ile sıcaklık değişimi arasındaki ilişkiyi doğru olarak açıklamasına rağmen, bu ilişkiyi yanlış bir tepkime üzerinden gösterdiği, bazı adayların ise yanlış bir tepkime yazıp açıklama yapmadığı görülmüştür.

Öğretmen adaylarının \% 66,7'si “Analiz" seviyesinde yer alan 4. soruya kısmen doğru cevap vermiştir. Cevaplar incelendiğinde, çoğunun toprağın tamponlama özelliği kalktığında $\mathrm{pH}$ değeri değişeceği için bitkilerin bundan olumsuz etkileneceğini belirttikleri görülmüş fakat toprağın $\mathrm{pH}$ değerinin değişmesinin bitkiler için neden önemli olduğunu belirtmedikleri görülmüştür. Ancak öğretmen adaylarının çok az bir kısmı toprağın tamponlama özelliği ile toprağın $\mathrm{pH}$ değeri arasındaki ilişkiyi tam olarak kurabilmiştir. Yanlış cevap veren öğretmen adaylarının ise, toprağın tamponlama özelliğinin önemini tam olarak kavrayamadığı görülmüştür. 
Öğretmen adaylarının \%71,4'ü "Bilgi" seviyesinde yer alan 5. soruya doğru cevap vermiştir. Cevaplar incelendiğinde, çoğunun demir korozyonun gerçekleşmesi için gerekli olan şartları sıraladığı görülmüştür.

Öğretmen adaylarının \%95,2'si “Değerlendirme" seviyesinde yer alan 6 . soruya yanlış cevap vermiştir. Cevaplar incelendiğinde, bu soruyu doğru cevaplama oranın çok düşük olduğu görülmüsstür. Öğretmen adaylarının çoğu bu soruya herhangi bir açıklama yapmamıştır.

Öğretmen adaylarının \%73,8'i "Kavrama" seviyesinde yer alan 7. soruya kısmen doğru cevap vermiştir. Öğretmen adaylarının verdikleri cevaplar incelendiğinde, çoğunun tam olmasa bile sert suların neden olduğu problemleri siralayabildiği görülmüştür. Sert sular çeşitli mutfak gereçlerinde ve yüzeylerde tortulara ve lekelere neden olur, sert sular daha çok sabun ve deterjan tüketilmesine neden olur, sert sular kireç oluşumuna neden olur gibi ifadeler öğretmen adaylarının sert suların neden olduğu problemlere verdikleri örneklerden bazılarıdır.

Öğretmen adaylarının \%71,4'ü "Değerlendirme" seviyesinde yer alan 8 . soruya kısmen doğru cevap vermiştir. Öğretmen adaylarının verdikleri cevaplar incelendiğinde, çoğunun bu soruya evet cevab1 verdiği görülmüsstür. Evet, cevabı verenlerin bir kısmı aktif karbonun absorbsiyon özelliği ile sudaki bazı kirleticileri absorbladığını belirtirken, bir kısmı yanlış açıklama yapmıştır.

Tablo 2 incelendiğinde, öğretmen adaylarını "Bilgi" seviyesinde yer alan 1. soruya "Kimyasal kinetiği tanımlayını" \%80, "Kavrama" seviyesinde yer alan 4. soruya "Maddede meydana gelen fiziksel ve kimyasal değişimler arasındaki farklılıklar nelerdir?" \%66.7 ve "Uygulama" seviyesinde yer alan 5. soruya "Katalizör kullanımı reaksiyon hızını nasıl etkilemektedir?" ise \% 50 oranında kısmen doğru cevap vermiştir.

Tablo 2. İkinci ögretim yılında uygulanan final sinavı sorularına ögretmen adaylarının verdikleri cevapların frekans ve yüzde dăgllımları

\begin{tabular}{|c|c|c|c|c|c|c|c|c|c|c|}
\hline & \multirow{2}{*}{ Sorular } & & \multicolumn{2}{|c|}{$\begin{array}{l}\text { Doğru } \\
\text { cevap }\end{array}$} & \multicolumn{2}{|c|}{$\begin{array}{c}\text { Kismen } \\
\text { doğru } \\
\text { cevap }\end{array}$} & \multicolumn{2}{|c|}{$\begin{array}{l}\text { Yanlış } \\
\text { cevap }\end{array}$} & \multicolumn{2}{|c|}{ Cevapsız } \\
\hline & & & $f$ & $\%$ & $f$ & $\%$ & $f$ & $\%$ & $\mathrm{f}$ & $\%$ \\
\hline \multirow{3}{*}{ 包: } & Analiz seviyesi & 2.soru & 19 & 63.3 & 5 & 16.7 & 6 & 20 & 0 & 0 \\
\hline & Analiz seviyesi & 3.soru & 4 & 13.3 & 24 & 80 & 2 & 6.7 & 0 & 0 \\
\hline & Sentez seviyesi & 6.soru & 0 & 0 & 0 & 0 & 29 & 96.7 & 1 & 3.3 \\
\hline \multirow{3}{*}{ 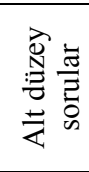 } & Bilgi seviyesi & 1.soru & 2 & 6.7 & 24 & 80 & 0 & 0 & 4 & 13.3 \\
\hline & $\begin{array}{l}\text { Kavrama } \\
\text { seviyesi }\end{array}$ & 4.soru & 10 & 33.3 & 20 & 66.7 & 0 & 0 & 0 & 0 \\
\hline & $\begin{array}{l}\text { Uygulama } \\
\text { seviyesi }\end{array}$ & 5.soru & 1 & 3.3 & 15 & 50 & 14 & 46.7 & 0 & 0 \\
\hline
\end{tabular}


Öğretmen adaylarının üst düzey düşünme gerektiren sorulardaki performansları incelendiğinde, "Analiz" seviyesinde yer alan 2. soruya "Kat1 faz yüzey alanı büyüklüğü ile reaksiyon hızı arasındaki ilişkiyi açıklayınız" \% 63.3 oranında doğru cevap verdikleri, "Analiz" seviyesinde yer alan 3 . Soruya "pH ile asitlik ve alkalilik arasındaki ilişkiyi açıklayınız" \% 80 oranında kısmen doğru cevap verdikleri görülmüsstür. Fakat "Sentez" seviyesinde yer alan 6. Soruya "Homojen karışımları ayırmada kromotografi yönteminin kullanımı hangi durumlarda uygun olabilir?" \%96.7 oranında yanlış cevap verdikleri görülmüştür. Ayrıca öğretmen adaylarının bu sorulara verdikleri cevaplar soru bazında incelenmiştir.

Öğretmen adaylarının \%80'i "Bilgi" seviyesinde yer alan 1. soruya kısmen doğru cevap vermiştir. Cevaplar incelendiğinde, çoğunun kimyasal kinetiğin sadece reaksiyon hızını ve reaksiyon hızına etki eden faktörleri içerdiğini ifade ettiği görülmüştür. Fakat kimyasal kinetiğin, ifade edilenlere ek olarak reaksiyonların mekanizmasını da kapsadığı hakkında fikir belirtmemişlerdir.

Öğretmen adaylarının \% 63,3'ü “Analiz” seviyesinde yer alan 2. soruya doğru cevap vermiş̧ir. Cevaplar incelendiğinde, bir kısmının katı faz yüzey alanı büyüklügü̈ arttıkça reaksiyon hızının da artacağını ifade etmelerine rağmen, bunu nedenini açıklayamadıkları görülmüştür. Öğretmen adaylarının diğer bir kısmı ise, yüzey alanı büyüklüğü arttıkça reaksiyona girecek tanecik sayısının artacağını belirtirken, bunun hız ile nasıl bir ilişkisi olduğunu açıklamamıştır.

Öğretmen adaylarının \%80'i “Analiz” seviyesinde yer alan üst düzey düşünme becerisi gerektiren 3. soruya kısmen doğru cevap vermiştir. Cevaplar incelendiğinde, çoğunun $\mathrm{pH}$ 'nın artıp azalması ile asitlik ve alkaliliğin değiştiğini ifade etmelerine rağmen, bu değişimin neye bağlı olarak gerçekleştiğini belirtmedikleri görülmüştür. pH'nın ne ifade ettiğini belirten öğretmen adayı sayısının oldukça az olduğu görülmüştür.

Öğretmen adaylarının \%66,7'si "Kavrama" seviyesinde yer alan 4. soruya kısmen doğru cevap vermiştir. Cevaplar incelendiğinde, genel olarak fiziksel değişimin maddenin iç yapısı değişmeden sadece dış görünüşünde meydana gelen değişim ve kimyasal değişimin ise maddenin kimyasal özelliklerinin değişimine neden olan değişim olduğunu ifade ettikleri yani bu değişimler sırasında maddenin hangi özelliklerinin değiştiğini bildikleri görülmüştür. Fakat çoğunun bu değişimlerin geri dönüşümlü olup olmadığı hakkında fikir belirtmedikleri görülmüştür.

Öğretmen adaylarının \%50'si "Uygulama" seviyesinde yer alan 5. soruya kısmen doğru cevap vermiştir. Öğretmen adaylarının çoğunun katalizörlerin tepkimelerin aktifleşme enerjisini düşürerek tepkimelerin hızını artırdığını ifade etmesine rağmen, tepkimelerin aktifleşme enerjisinin düşürülmesi ile tepkime hızının neden arttığını belirtmedikleri görülmüştür. 
Öğretmen adaylarının çoğunun katalizörlerin tepkime mekanizmasına nasıl etki ettiği hakkında fikir belirtmedikleri görülmüsstür. Sadece bir öğrenci, katalizörlerin tepkime mekanizmasını değiştirdiğini yani tepkimelerin daha farklı bir yol izlemesine neden olarak tepkime hızını arttırdığını belirtmiştir. Öğretmen adaylarının bir kısmının ise, katalizörlerin tepkime hızını arttırdı̆̆ını belirtmelerine rağmen, bunun nedenini açıklamadıkları görülmüştür.

Öğretmen adaylarının \%96,7'si "Sentez" seviyesinde yer alan 6. soruya yanlış cevap vermiştir. Bu soruyu doğru cevaplama oranının çok düşük olduğu görülmüştür. Öğretmen adaylarının çoğu bu soruya cevap olarak kromotografi yönteminin tanımını yapmış fakat bu yöntemin homojen karışımları ayırmak için hangi durumlarda kullanıldığı hakkında bir açıklama yapmamıştır.

\section{Üçüncü Alt Probleme İlişkin Bulgular}

Çalışmanın üçüncü alt problemi ile ilişkili olarak; çoklu doğrusal regresyon analizi yapılmıştır. Bulgular, Tablo 3'te verilmektedir.

Tablo 3. PÇBAE, BIBTT ve MDYT son test sonuçlarl ve performans ile ilgili çoklu doğrusal regresyon analizi bulgularl

\begin{tabular}{|c|c|c|c|c|c|c|c|}
\hline \multirow[t]{2}{*}{ Model } & \multicolumn{2}{|c|}{$\begin{array}{l}\text { Standartlaşmamış } \\
\text { katsayılar }\end{array}$} & \multirow{2}{*}{$\begin{array}{c}\text { Stand. } \\
\text { katsayilar } \\
\text { Beta }\end{array}$} & \multirow[b]{2}{*}{$\mathrm{t}$} & \multirow[b]{2}{*}{$\mathrm{p}$} & \multirow[b]{2}{*}{ İkili r } & \multirow[b]{2}{*}{ Kismi r } \\
\hline & $\mathrm{B}$ & Std. Hata & & & & & \\
\hline Sabit & 70,762 & 8,933 & & 7,921 & ,000 & & \\
\hline PÇBE &,- 200 & ,067 &,- 310 & $-2,987$ & 004 &,- 474 &,- 341 \\
\hline BİBT & $-2,01 \times 10^{-2}$ & 085 &,- 025 &,- 237 & 813 &, 303 &,- 029 \\
\hline MDYT & 2,841 &, 632 & ,476 & 4,496 & 000 &, 578 & 479 \\
\hline
\end{tabular}

$\mathrm{R}=, 644, \mathrm{R}^{2}=, 415, \mathrm{~F}=16,064, \mathrm{p}=, 000$, Bağımlı değişken: Performans, Bağımsız değişkenler: PÇBA, BİB ve MDY

Uygulamalardan sonra öğretmen adaylarının performanslarındaki değişimin \%42'sinin modele dahil edilen PÇBA, BİB ve MDY değişkenleri tarafindan birlikte açıklandığı Tablo 3'te görülmektedir. Regresyon analizi sonuçlarına göre, öğretmen adaylarının performanslarının yordanmasına ilişkin regresyon eşitliği (matematiksel model) aşağıdaki gibidir;

Performans $=70,762-0,200$ PÇBA $-2,01 \times 10-2$ BİB $+2,841$ MDY

Geriye kalan \% 58'lik kısım ise, hata terimi vasitasıyla modele dahil edilmeyen değişkenler tarafından açıklanmaktadır. $\mathrm{F}=16,064$ değeri, modelin bir bütün olarak her düzeyde anlamlı olduğunu göstermektedir $(\mathrm{R}=$ ,644, $\left.\mathrm{R}^{2}=, 415, \mathrm{~F}=16,064, \mathrm{p}=, 000\right)$. Standardize edilmiş regresyon katsayısına (Beta) göre ise, yordayıcı değişkenlerin öğretmen adaylarının 
performansları üzerindeki göreli önem sırası; MDY, PÇBA ve BİB şeklindedir. Regresyon katsayılarının anlamlılığına ilişkin t-testi sonuçları birlikte incelendiğinde, PÇBA ve MDY değişkenlerinin öğretmen adaylarının performanslarının anlamlı bir yordayıcı olduğu görülmektedir. BİB değişkeninin ise anlamlı bir etkiye sahip olmadığg görülmektedir.

\section{SONUÇLAR VE TARTIŞMA}

Çalışmanın birinci alt problemiyle ilişkili olarak, öğretmen adaylarının performansları incelendiğinde, performans puanlarının en düşük 58 , en yüksek 94 olduğu belirlenmiştir. Öğretmen adaylarının performans ortalamaları ise $\bar{X}=76.64$ olarak bulunmuştur. $\mathrm{Bu}$ ortalamaya göre öğretmen adaylarının performanslarının iyi olduğu söylenebilmektedir.

İkinci alt problemle ilişkili olarak, öğretmen adaylarının final sınavlarındaki performansları incelendiğinde, "Analiz" seviyesindeki sorulara genellikle kısmen doğru cevap verdikleri, "Sentez" ve "Değerlendirme" gerektiren sorulara daha çok yanlış cevap verdikleri görülmüştür. Öğretmen adayları "Bilgi", "Kavrama" ve "Uygulama" seviyelerindeki sorulara ise genellikle doğru ve kısmen doğru cevap vermiştir. $\mathrm{Bu}$ sonuçlar doğrultusunda, öğretmen adaylarının alt düzey düşünme becerisi gerektiren sorulardaki performanslarının üst düzey düşünme becerisi gerektiren sorulardakinden daha iyi olduğu söylenebilmektedir.

Çalışmanın üçüncü alt problemiyle ilişkili olarak, uygulamalar sonucunda öğretmen adaylarının performanslarındaki değişimin \%42'sinin modele dahil edilen PÇBA, BİB ve MDY değişkenleri tarafından birlikte yordandığ 1 belirlenmiştir.

Tablo 3'teki ikili korelasyonlar incelendiğinde, öğretmen adaylarının PÇBA puanları ile performansları arasında orta düzeyde, negatif ve anlamlı bir ilişkinin $(\mathrm{r}=-0,47 ; \mathrm{p}=.004)$ olduğu görülmüştür. Yani öğretmen adaylarının problem çözme becerisini algılama puanlarının arttı̆g 1 durumda performanslarının azaldığı görülmektedir. Taylan (1990)'a göre PÇBAE'den alınan yüksek puanlar, problemler karşısında etkili çözümler bulamamayı göstermekte, problem çözme becerisinin düşük olduğunu ifade etmektedir. Elde edilen bu sonuç, problem çözme becerisini iyi olarak algılayan öğretmen adaylarının performanslarının yüksek olduğunu, problem çözme becerisini iyi olarak algılamayan öğretmen adaylarının performanslarının düşük olduğunu göstermektedir.

Literatürde problem çözme becerisi ile performans arasındaki ilişkiyi inceleyen çalışmalar yer almaktadır. Geban, Aşkar ve Özkan (1992) çalışmaları sonucunda, bilgisayar simülasyon deneyi yaklaşımı ile problem 
çözme yaklaşımının uygulandığı deney grubundaki öğrencilerin kimya başarısının geleneksel yaklaşımın uygulandığı kontrol grubundaki öğrencilere göre daha yüksek olduğunu bulmuşlardır. Su (2008), çalışmasında öğrencilerin problem çözme becerilerini geliştirmek için multimedya teknolojisinin problem çözmede kullanılmasını önermiştir. Öğrencilerin performansları incelendiğinde, kavramsal problem çözme yeteneği açısından, deney grubundaki öğrencilerde, önemli bir gelişmenin olduğu gözlenirken, kontrol grubundaki öğrenciler de ise herhangi bir gelişme gözlenmemiştir. Jeon, Huffman ve Noh (2005), çalışmalarında "Yüksek sesle düşünerek eşli problem çözme" (YSDEPÇ) yaklaşımını kullanmışlardır. Çalışmanın sonucunda YSDEPÇ grubundaki öğrencilerin, kavramsal bilgi açısından diğer grup öğrencilerine göre daha iyi performans gösterdikleri belirlenmiștir.

Tablo 3'teki ikili korelasyonlar incelendiğinde, öğretmen adaylarının bilimsel işlem becerileri ile performansları arasında pozitif ve orta düzeyde bir ilişkinin $(\mathrm{r}=0,30)$ olduğu görülmüştür. Fakat regresyon katsayılarının anlamlılığına ilişkin t-testi sonuçları birlikte incelendiğinde, BİB değişkeninin performans üzerinde anlamlı bir etkiye sahip olmadığı belirlenmiştir $(\mathrm{p}=, 813)$. Bilimsel işlem becerileri daha çok laboratuvarla ilgili pratik uygulama becerileri olduğu için elde edilen bu sonucun nedeni olarak, öğretmen adaylarının performanslarının bilimsel işlem becerilerini değerlendirmeye yönelik bir tarzda yapılmamış olması gösterilebilir.

Literatür incelendiğinde, öğrencilerin laboratuvar uygulamaları sonucunda bilimsel işlem becerilerinin artıp artmadığını inceleyen çalışmaların olduğu görülmüștür (Goh, Toh ve Chia, 1989; Koray, Köksal, Özdemir ve Presley, 2007; Suits, 2004). Geban, Aşkar ve Özkan (1992) ise çalışmalarında, problem çözme yönelimli kimya laboratuvar etkinlikleri sonucunda öğrencilerin bilimsel işlem becerilerinin artıp artmadığını incelemiştir. Fakat problem çözme odaklı laboratuar uygulamaları sonucunda elde edilen problem çözme performansı ile bilimsel işlem becerileri arasındaki ilişkiyi inceleyen çalışmalara rastlanmamıştır. Problem çözme performansı ile bilimsel işlem becerisi arasındaki ilişkiyi inceleyen Babayeva (2000) ise çalışması sonucunda öğrencilerin algoritmik problem çözme yetenekleri ve bilimsel işlem becerileri ile kavramsal öğrenmeleri arasında anlamlı bir ilişkinin olduğunu ortaya çıkarmıştır. Fakat bu çalışmanın sonucunun çalışmamızın sonucu ile uyumlu olmadığı görülmüştür.

Tablo 3'teki ikili korelasyonlar incelendiğinde, öğretmen adaylarının mantıksal düşünme yetenekleri ile performansları arasında pozitif, yüksek ve anlamlı düzeyde bir ilişkinin $(r=0,58 ; p=, 000)$ olduğu görülmüştür.

Literatür incelendiğinde problem çözme odaklı laboratuar uygulamaları sonucunda elde edilen problem çözme performansı ile mantıksal düşünme 
yeteneği arasındaki ilişkiyi inceleyen çalışmalara rastlamazken, problem çözme performansı ile mantıksal düşünme yeteneği arasındaki ilişkiyi inceleyen çalışmalara rastlanmıştır. $\mathrm{Bu}$ çalışmaların sonuçlarının çalışmamızın sonucunu destekler nitelikte olduğu görülmüsştür. Bilgin (2006) çalışmasında, Polya'nın problem çözme stratejisi ile birleştirilmiş eşli problem çözme tekniğinin öğrencilerin kavramsal ve algoritmik kimya sorularını çözme performansları üzerine etkisini incelemiştir. Yapılan analiz sonucunda, mantıksal düşünme yeteneği testi puanlarının, algoritmik soru testi son test puanları ve kavramsal soru testi son test puanları üzerinde anlamlı bir etkisinin olduğu görülmüsstür. Cracolice, Deming ve Ehlert (2008), çalışmalarında kavramsal ve algoritmik problem çözme yetenekleri arasındaki farkın zayıf mantıksal düşünme yeteneği olduğu şeklindeki hipotezlerini test etmeyi amaçlamışlardır. Mantıksal düşünme yeteneği iyi ve zayıf olan öğrencilerin performansları karşılaştırıldığında, daha iyi mantıksal düşünme yeteneğine sahip olan öğrencilerin soruları çözme performansları daha iyi bulunmuştur. BouJaoude, Salloum ve Abd-ElKhalick (2004) çalışmaları sonucunda, üç bilişsel değişkenin (öğrenme oryantasyonu, formal mantıksal düşünme ve zihin kapasitesi) öğrencilerin kavramsal kimya problemlerini çözme performanslarının anlamlı yordayıcısı olduğu sonucuna ulaşmışlardır. Niaz (1993) çalışmasında, öğrencilerin kimya problemlerini çözerken kullandıkları mantıksal düşünme stratejilerini, mantıksal düşünme yeteneğinin, M-kapasitesinin (bilgiyi işleme değişkeni) ve alana bağımlılık/alandan bağımsızlık değişkeninin bir fonksiyonu olarak incelemiştir. Çalışmanın sonuçları, bilişsel değişkenler açısından yüksek puan alan öğrencilerin kimya problemlerini çözmede daha iyi olduklarını, mantıksal düşünme stratejileri kullandıklarını göstermiştir. Engemann (2000), çalışmasında problem çözme performansının, mantıksal düşünme ve zihinsel kapasite arasında var olan etkileşim ile ilgili olduğunu rapor etmiştir. Nammouz (2005) çalışması sonucunda mantıksal düşünme yeteneği ve öğrencilerin problem çözme performansları arasında ilişki bulmuştur.

\section{ÖNERILER}

Çalışmamızda öğretmen adaylarının aktif katılımını gerektiren, onların yaratıc1 ve eleştirel düşünmelerine, öğrenmelerinin sorumluluğunu almalarına, araştırma yapmalarına, mantıklı kararlar vererek kendilerine sunulan problem durumlarına çözümler bulmalarına, bilimsel işlem becerilerini kullanarak problemlerini çözmelerine, problemlerine çözüm bulmaları yoluyla yeni bilgi elde etmelerine olanak sağlayan öğrenci merkezli bir yaklaşım kullanılmıştır. Bu yaklaşımın öğrencilere sağladıkları yararlar düşünüldüğünde, eğitmenler derslerinde öğrenci merkezli yaklaşımlara daha fazla yer vermelidir. 
Çalışmamızda öğretmen adayları kendilerine sunulan problem durumlarına çözüm arama sürecinde laboratuvar etkinliklerinde yer almışlar ve böylece problemlerine çözüm bulabilmiştir. Laboratuar etkinliklerini kapsayan böyle bir problem çözme yaklaşımı, laboratuvar uygulamalarının geleneksel laboratuvar uygulamalarından farklı olarak, öğrencilere daha fazla yarar sağlayacak şekilde düzenlenmesi gerekliliğini ortaya koymaktadır. Bu nedenle, kalıcı ve verimli öğrenmenin sağlanabilmesi için, ögrencilerin kendi deneyimlerine dayalı yaparak yaşayarak öğrendikleri laboratuvar etkinliklerinde yer almaları sağlanmalıdır.

Çalışmamızda gerçekleştirilen kimya laboratuvarında problem çözme uygulamaları, her iki öğretim yılında uygulamaların yürütüldüğü derslere kayıtlı öğretmen adayı sayısının sinırlılığından dolayı tek grup ile yürütülmüştür. Çalışmada yer alan değişkenlerin karşılaştırmalı olarak incelenmesi için çalışmanın deney kontrol gruplu olarak yürütülmesinin daha verimli olacağı düşünülmektedir.

\section{KAYNAKLAR}

Altun, M. ve Arslan, Ç. (2006). İlköğretim öğrencilerinin problem çözme stratejilerini öğrenmeleri üzerine bir çalışma. Uludağ Üniversitesi Eğitim Fakültesi Dergisi, XIX (1), 1-21.

Aydoğdu, B. (2006). Illköğretim fen ve teknoloji dersinde bilimsel süreç becerilerini etkileyen değişkenlerin belirlenmesi. Yüksek lisans tezi, Dokuz Eylül Üniversitesi, İzmir.

Babayeva, E. (2000). Ortä̈ğretim 10. sinlf ögrencilerinin gaz kanunlartyla ilgili kavramsal ögrenme ile problem çözme yeteneğinin karşılaştırılması. Yüksek lisans tezi, Gazi Üniversitesi, Ankara.

Bilgin, İ. (2006). The effects of pair problem solving technique incorporating polya's problem solving strategy on undergraduate students' performance in chemistry. Journal of Science Education, 7(2), 101-106.

Bloom, B.S. (Ed.), Engelhart, M. D., Furst E. J. et al. (1965). Taxonomy of educational objectives-the classification of educational goals, New York: David McKay Company.

BouJaoude, S., Salloum, S. \& Abd-El-Khalick, F. (2004). Relationships between selective cognitive variables and students' ability to solve chemistry problems. Research report. International Journal of Science Education, 26(1), 63-84.

Bozdoğan, A. (2007). Fen bilgisi öğretiminde çalışma yaprakları ile öğretimin ögrencilerin fen bilgisi tutumuna ve mantıksal düşünme becerilerine etkisi. Yüksek lisans tezi, Çukurova Üniversitesi, Adana.

Cardellini, L. (2006). Fostering creative problem solving in chemistry through group work. Chemistry Education Research and Practice, 7 (2), 131-140.

chem.ntci.on.ca/sch4u/InquiryRubric.pdf adresinden 8 Ekim 2007tarihinde erişilmiştir.

Chiappetta, E. L. \& Koballa, T. R. (2002). Science instruction in the middle and secondary schools $\left(5^{\text {th }}\right.$ Ed.). Upper Saddle River, NJ: Merrill/Prentice Hall. 
Cracolice, M. S., Deming, J. C. \& Ehlert, B. (2008). Concept learning versus problem solving: A cognitive difference. Journal of Chemical Education, 85(6), 873-878.

Engemann, J. F. (2000). Performance in chemistry problem solving: a study of expert/novice strategies and specific cognitive factors. A Dissertation submitted to the Faculty of the Graduate School of State University of New York at Buffalo in partial fulfillment of the requirements for the Degree of Doctor of Philosophy.

Erbaş, S., Şimşek, N. ve Çınar, Y. (2005). Fen bilgisi laboratuarı ve uygulamaları (1.Baskl). Ankara: Nobel Yayın Dağıtım.

Finster, D.C. (1991). Developmental instruction, Part II. application of the Perry model to general chemistry. Journal of Chemical Education, 68(9), 752-756.

Gallet, C. (1998). Problem-solving teaching in the chemistry laboratory: Leaving the cooks... Journal of Chemical Education, 75(1), 72-77.

Geban, Ö., Aşkar, P. \& Özkan, İ. (1992). Effects of computer simulations and problem-solving approaches on high school students. Journal of Educational Research, 86(1), 5-10.

Germann, P. J. (1994). Testing a model of science process skills acquisition: an interaction with parents' education, preferred language, gender, science attitude, cognitive development, academic ability, and biology knowledge. Journal of Research in Science Teaching, 31(7), 749-783.

Germann, P. J., Haskins, S., \& Auls, S. (1996). Analysis of nine high school biology laboratory manuals: Promoting scientific inquiry. Journal of Research in Science Teaching, 33(5), 475499.

Goh, N. K., Toh, K. A. \& Chia, L. S. (1989). Use of modified laboratory instruction for improving science process skills acquisition. Journal of Chemical Education, 66(5), 430-432.

Güçlü, N. (2003). Lise müdürlerinin problem çözme becerileri. Milli Eğitim Dergisi, 160.

Heppner. P.P. \& Petersen, C. H. (1982). The development and implications of a personal problem solving inventory. Journal of Counseling Psychology, 29(1), 66-75.

Herron J. D. \& Greenbowe, T. J. (1986). What can we do about Sue: a case study of competence. Journal of Chemical Education, 63(6), 530.

Jeon, K., Huffman, D. \& Noh, T. (2005). The effects of thinking aloud pair problem solving on high school students' chemistry problem-solving performance and verbal interactions. Journal of Chemical Education, 85(10), $1558-1564$.

Karahan, Z. (2006). Fen ve teknoloji dersinde bilimsel süreç becerilerine dayalı ögrenme yaklaşımının ögrenme ürünlerine etkisi. Yüksek lisans tezi, Zonguldak Karaelmas Üniversitesi, Zonguldak.

Koray, Ö., Köksal, M. S., Özdemir, M. \& Presley, A. İ. (2007). The effect of creative and critical thinking based laboratory applications on academic achievement and science process skills. Elementary Education Online, 6(3), 377-389.

Lee, K. W. L., Tang, W. U., Goh, N.K.. \& Chia, L. S. (2001). The predicting role of cognitive variables in problem solving in mole concept. Chemistry Education Research and Practice, 2(3), 285-301. 
Lynch, C. L., Wolcott, S. K., and Huber, G. E. (2000). Tutorial for optimizing and documenting open-ended problem solving skills [On-line]. Available: http://home.apex.net/ leehaven.

Nammouz, M. S. (2005). A study of the effects that grouping laboratory partners based on logical thinking abilities have on their problem solving strategies in a general chemistry course. A Dissertation presented to the Graduate School of Clemson University, in partial fulfillment of the requirements for the Degree of Doctor of Philosophy Curriculum and Instruction: Chemical Education.

Neeland, E. G. (1999). An introductory organic lab for the problem-solving lab approach. Journal of Chemical Education, 76(2), 230-231.

Niaz, M. (1993). Reasoning strategies of students in solving chemistry problems as a function of developmental level, functional M-capacity and disembedding ability, Reports-Research/Technical. Paper presented at the Annual Meeting of the National Association for Research in Science Teaching, Atlanta, GA.

Okey, J. R., Wise, K. C. \& Burns J. C. (1982). Integrated process skill test-2, (Available from Dr. James R. Okey, Department of Science Education, University of Georgia, Athens, GA 30362).

Reif, F., Larkin, B. H. ve Brackett, G. C. (1976). Teaching general learning and problem-solving skills. American Journal of Physics, 44(3), 212-217.

Renner, J. W. (1986). Rediscovering the Lab. The Science Teacher, 44-45.

Savaşır, İ. ve Şahin. N. H. (1997). Bilişşsel-davranış̧̧ı terapilerde değerlendirme: sık kullanılan ölçekler. Ankara: Türk Psikologlar Derneği Yayınları.

Saygıll, H. (2000). Problem çözme becerisi ile sosyal ve kişisel uyum arasındaki ilişskinin incelenmesi. Yüksek Lisans Tezi, Atatürk Üniversitesi, Erzurum.

Sonmaz, S. (2002). Problem çözme becerisi ile yaratıcllı ve zeka arasındaki ilişkinin incelenmesi. Yayınlanmamış Yüksek Lisans Tezi, Marmara Üniversitesi, İstanbul.

$\mathrm{Su}, \mathrm{K}-\mathrm{D}$. (2008). An informative study of integrating multimedia technology into problem-solving for promoting students' abilities in general chemistry. Int'l $J$ Instructional Media, 35(3), 339-353.

Suits, J. P. (2004). Assessing investigative skill development in inquiry-based and traditional college science laboratory courses. School Science and Mathematics, 104(6), 248-257.

Taylan, S. (1990). Heppner'in Problem Çözme Envanterinin Uyarlama, Güvenirlik ve Geçerlik Çalışmaları. Yayınlanmamış yüksek lisans tezi, Ankara Üniversitesi, Ankara.

Tobin, K. \& Copie, W. (1981). Test of logical thinking. Educational and. Psychological Measurement, 41(2), 413-424.

Yaman, S. (2005). Fen Bilgisi Öğretiminde Probleme Dayalı Öğrenmenin Mantıksal Düşünme Becerisinin Gelişimine Etkisi. Türk Fen Eğitimi Dergisi, 2(1), 56-70.

YÖK Dünya Bankası, (1997). Milli Eğitimi Geliştirme Projesi, Hizmet Öncesi Ö̆gretmen Ĕ̆itimi, Ankara, Türkiye.

Wilson, H. J. (1987). Problem-solving laboratory exercises. Journal of Chemical Education, 64 (10), 895-896. 